\title{
Thermal Hydraulic Analysis of 3 MW TRIGA Research Reactor of Bangladesh Considering Different Cycles of Burnup
}

\author{
M.H. Altaf and N.H. Badrun* \\ Reactor Physics and Engineering Division (RPED), Institute of Nuclear Science and Technology (INST) \\ Atomic Energy Research Establishment (AERE), Ganakbari, Savar, Dhaka-1349, Bangladesh
}

\section{ARTICLE INFO}

\section{Article history:}

Received 09 September 2014

Received in revised form 21 December 2014

Accepted 22 December 2014

Keywords:

TRIGA reactor

Burnup

Thermal hydraulic

EUREKA-2/RR

\begin{abstract}
A B S T R A C T
Burnup dependent steady state thermal hydraulic analysis of TRIGA MarkII research reactor has been carried out utilizing coupled point kinetics, neutronics and thermal hydraulics code EUREKA-2/RR. From the previous calculations of neutronics parameters including percentage burnup of individual fuel elements performed so far for 700 MWD burnt core of TRIGA reactor showed that the fuel rod predicted as hottest at the beginning of cycle (fresh core) was found to remain as the hottest until 200 MWD of burn, but, with the progress of core burn, the hottest rod was found to be shifted and another rod in the core became the hottest. The present study intends to evaluate the thermal hydraulic parameters of these hottest fuel rods at different cycles of burnup, from beginning to $700 \mathrm{MWD}$ core burnt considering reactor operates under steady state condition. Peak fuel centerline temperature, maximum cladding and coolant temperatures of the hottest channels were calculated. It revealed that maximum temperature reported for fuel clad and fuel centerline found to lie below their melting points which indicate that there is no chance of burnout on the fuel cladding surface and no blister in the fuel meat throughout the considered cycles of core burnt.
\end{abstract}

(C) 2014 Atom Indonesia. All rights reserved

\section{INTRODUCTION}

The 3-MW TRIGA Mark-II research reactor is the only reactor of Bangladesh that has been in operation over the last 27 years. Since its commissioning in 1986, the reactor has been engaged in production of radio-isotopes for uses in agriculture, industry and medicine all over the country as well as in conducting research and manpower training in various fields of nuclear science. To make the most effective use of reactor with the extension of its core life time, efforts have been paid in improving its in-core fuel management of the reactor by the calculation of different necessary parameters including individual fuel burnup at different cycles of reactor operation. Contribution of Huda et al. [1], Rahman et al. [2], Mahmood et al. [3] can be referred in this regard. In fact, for every modification of reactor core, it needs thermal hydraulic safety assessment prior to

\footnotetext{
* Corresponding author.

E-mail address: nhbadrun@yahoo.com
}

its utilization. From this concern, this paper deals with the calculation of thermal hydraulic parameters of TRIGA core to ensure reactor have sufficient safety margins at every cycles of burn up during normal operation. Coupled point kinetics, neutronics and thermal hydraulics code EUREKA-2/R has been utilized for this purpose.

The 3-MW TRIGA Mark-II research reactor is a pool type, zirconium hydride moderated and light water cooled reactor. It operates at a steady state thermal power of $3 \mathrm{MW}$ where the operation includes natural convection mode and forced convection cooling mode. In the natural convection mode, the fuel elements are cooled by water natural convection in the pool up to the maximum power level of $500 \mathrm{~kW}$ of the reactor. For higher power, forced convection cooling mode is required where heat removal system is provided for removing heat from the reactor pool water. The heat removal system contains a primary water system and a secondary water system. The primary system along with an online purification system contains the most unique design features. In the forced 
convection mode, coolant flow is maintained by simultaneous action of two pumps each supplying $50 \%$ of the total flow of $794 \mathrm{~m}^{3} / \mathrm{h}$ (3500 GPM). Heat generated in the reactor core is transferred to a water-to-water heat exchanger of primary loop, while the secondary loop water is cooled by an external cooling tower. It is worth noting that the reactor has a facility to operate at pulsing of $852 \mathrm{MW}$ power in case of 2.00 dollar $(1.4 \% \mathrm{dk} / \mathrm{k})$ of reactivity insertion. However, this facility is yet to be put in practice because no demand has been made from the users.

EUREKA-2/RR[4] provides a coupled thermal, hydraulic and point kinetics capability. Based on core neutronics calculation at different cycles of burnup, three other utility codes, namely, DISSUE, ICETEA and PREDISCO [5] are used in succession to support the entire analysis. Figure 1 shows the successive use of these codes in order to provide data in preparing the input of EUREKA-2/RR.

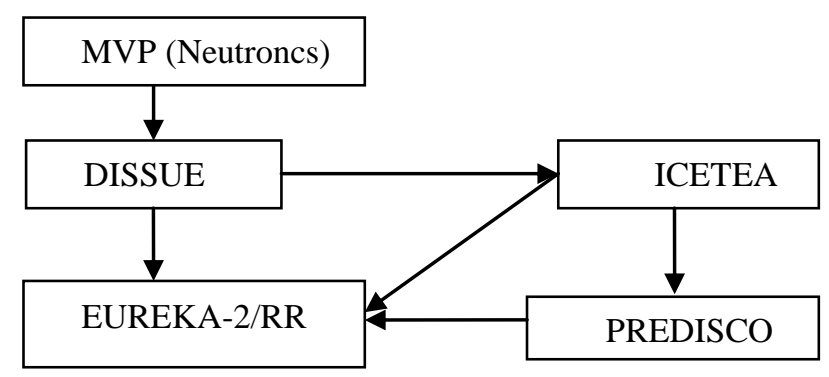

Fig. 1. An outline of the overall process followed in preparing the input of EUREKA-2/RR.

\section{EXPERIMENTAL METHODS}

\section{Neutronic studies of the triga core}

There is a link between neutronic analysis and thermal analysis of the reactor core since heat energy generated in the core is induced by the fission neutrons. If trace back reports of Huda et al.[1], Rahman et al. [2] , Mahmood et al. [3], it is recognized that individual fuel element burnup together with power peaking factors calculations have been carried so far for about 700 MWD burnt of TRIGA core until 2012. These previous calculations were mostly conducted by using three dimensional continuous energy Monte Carlo code MVP considering cross section data library JENDL3.3. If reviewing power peaking factors calculations at different cycles of burnup, it is found that $\mathrm{C} 4$ fuel element in the TRIGA core remains hottest up to 200 MWD and onward from this, $\mathrm{C} 10$ becomes the hottest rod that continued up to 700 MWD of core burnt, as it is seen in Fig. 2. The locations of $\mathrm{C} 4$ and C10 fuel elements can be identified from the configuration of TRIGA reactor core as shown in Fig. 3. Due to shifting of hottest rods with the progress of core burnup, the present study calculates thermal hydraulics parameters initially to the extent of 200 MWD core burnt which was later extended to perform two more calculations considering 550 MWD and 700 MWD burnup cycles. As C4 is the hottest rod from the beginning to 200 MWD cycles of burnup, radial and axial power peaking factors of C4 considering fresh core (beginning of cycle) as well as 75 MWD and 150 MWD burnt core are taken into account. Similarly, radial and axial power peaking factors of the hottest rod, C10, have been considered for 550 MWD and 700 MWD cycles of burnt core. Table 1 shows the radial, axial and total peaking factor for the hottest rods at different burnup cycles.

Table 1. Peaking factors of $\mathrm{C} 4$ and $\mathrm{C} 10$ at different burnup cycles.

\begin{tabular}{|c|c|c|c|c|c|}
\hline \multirow[t]{2}{*}{ Peaking Factors } & \multicolumn{2}{|c|}{$\mathrm{C} 4$} & \multicolumn{3}{|c|}{ C10 } \\
\hline & BOC & $\begin{array}{c}75 \\
\text { MWD }\end{array}$ & $\begin{array}{l}150 \\
\text { MWD }\end{array}$ & $\begin{array}{l}550 \\
\text { MWD }\end{array}$ & $\begin{array}{c}700 \\
\text { MWD }\end{array}$ \\
\hline $\begin{array}{l}\text { Radial Peaking } \\
\text { Factor }\end{array}$ & 1.668 & 1.660 & 1.651 & 1.651 & 1.652 \\
\hline $\begin{array}{l}\text { Axial Peaking } \\
\text { Factor }\end{array}$ & 1.218 & 1.222 & 1.225 & 1.285 & 1.304 \\
\hline $\begin{array}{l}\text { Total Peaking } \\
\text { Factor }\end{array}$ & 2.031 & 2.028 & 2.024 & 2.121 & 2.154 \\
\hline
\end{tabular}

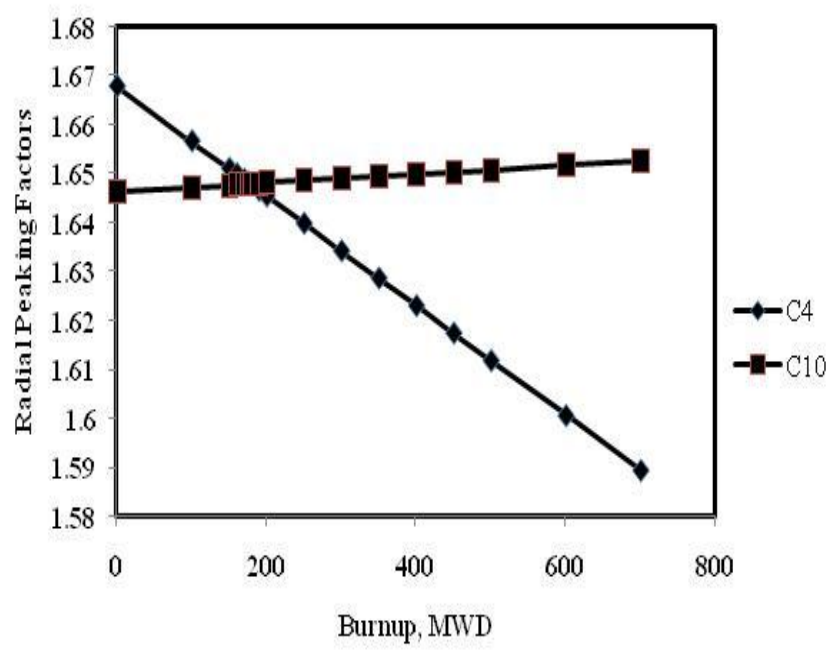

Fig. 2. Radial Peaking Factors of fuel elements C4 and C10 against core burnt. 


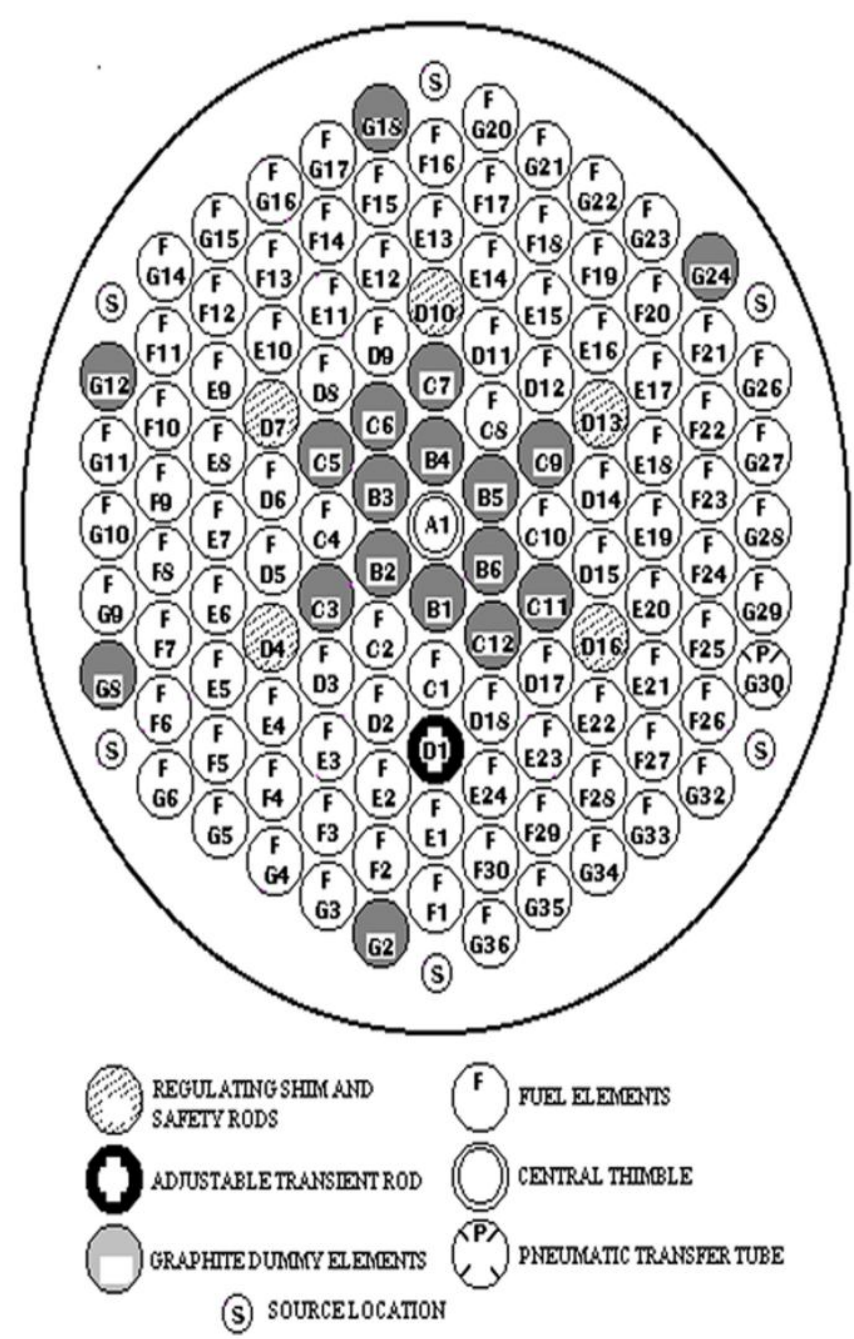

Fig. 3. Configuration of 3 MW TRIGA Mark-II Research Reactor.

\section{Analytical model of triga core}

For modeling, only fuel region in the core is considered. An upper and a lower plenum are located above and bottom of the core represent the reactor pool water as seen in Fig. 4.

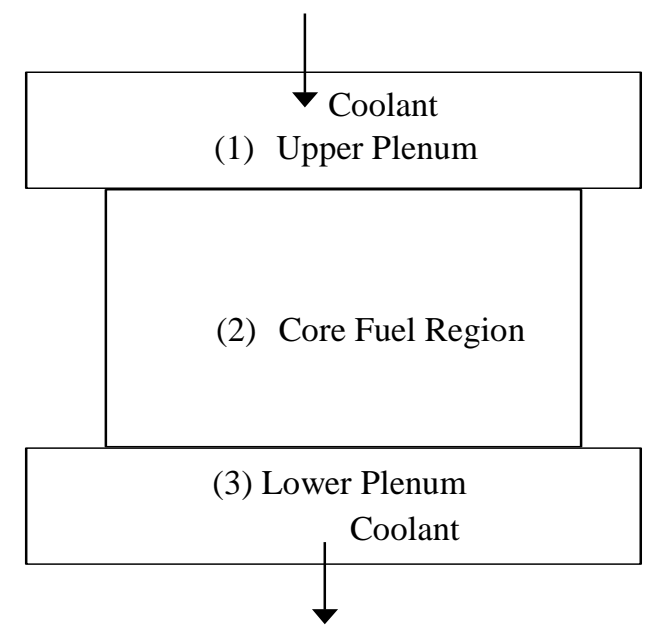

Fig. 4. Outline of an analytical model.
The core contains 95 fuel elements and 5 fuel follower elements are divided into 5 distinct channels. Each channel may contain one or more fuel elements. The distribution of these fuel elements among the channels are made on the basis of power peaking factors values of the fuel elements. The fuel rods in each channel are defined by heat conductors called as heat slabs while the coolant in the core is represented by several nodes and junctions. In the present model, each channel consists of 10 heat slabs along with 10 nodes as shown in the Fig. 5. The model in total then consists of 52 nodes, 50 heat slabs and 56 junctions. According to Fig. 5, Junction no. 56 is the fill junction used to simulate the primary coolant flow in the core. Table 2 gives other design parameters required for total thermal hydraulic analysis.

Detail about core modeling is introduced in my previously published work[6]. The same model that was validated before[6] under 
steady state condition has been reconsidered in this present study, but, the variation of power peaking factors with the progress of core burnt have been taken into account during simulation of each cycle of burnup. This study, hence, is a complementary study aim to investigate the reactor thermal hydraulic behaviors at different cycles of core burnup.

Table 2. Technical specification of TRIGA MARK-II Research Reactor.

\begin{tabular}{|c|c|}
\hline Parameters & Design Value \\
\hline Fuel Element (rod type) & $20 \%$ w/o U-ZrH, $19.7 \%$ enriched \\
\hline Total number of fuels in the core & 100 \\
\hline Cladding & Stainless Steel 304L \\
\hline Reflector & Graphite \\
\hline $\begin{array}{l}\text { Inlet Temperature }{ }^{\circ} \mathrm{C} \\
\text { (Full Power) }\end{array}$ & 40.6 \\
\hline Radius of $\mathrm{Zr}$ rod $(\mathrm{cm})$ & 0.3175 \\
\hline Fuel radius $(\mathrm{cm})$ & 1.82245 \\
\hline Clad outer radius $(\mathrm{cm})$ & 1.87706 \\
\hline Gap width $(\mathrm{cm})$ & 0.00381 \\
\hline Active fuel length $(\mathrm{cm})$ & 38.1 \\
\hline Flow area $\left(\mathrm{cm}^{2}\right)$ & 5.3326 \\
\hline Hydraulic Diameter (cm) & 1.80594 \\
\hline Pressure $(\mathrm{Pa})$ & $1.60654 \times 10^{5}$ \\
\hline Friction Loss Coefficient & 0.07 \\
\hline Pressure Loss Coefficient & 1.81 (inlet); 2.12 (Outlet) \\
\hline $\begin{array}{l}\text { Pitch }(\mathrm{cm}) \\
\text { Mass Flow rate, } \mathbf{k g} / \mathbf{m}^{2} \mathbf{s} \\
\text { (a) Natural Convection Mode }\end{array}$ & $\left\{\begin{array}{c}4.5716 \\
145.20(\text { at } 500 \mathrm{~kW}) \\
120.55(\text { at } 300 \mathrm{~kW}) \\
81.03(\text { at } 100 \mathrm{~kW})\end{array}\right.$ \\
\hline (b) Forced Convection Mode & $3.2089 \times 10^{3}$ \\
\hline $\begin{array}{l}\text { Coolant Velocity }(\mathbf{c m} / \mathbf{s e c}) \\
\text { (a) Natural Convection Mode } \\
\text { (b) Forced Flow }\end{array}$ & $\begin{array}{l}30.48 \\
287.58\end{array}$ \\
\hline
\end{tabular}

\section{Steady state thermal hydraulic analysis}

The objective of thermal hydraulic core analysis is to ensure the operational temperature in the core does not exceed the design limit of temperature. To investigate this maximum temperature, the common approach in practice is to sort out the hottest fuel rod from the core. If it can be ensured the hottest fuel rod exhibits the temperature that remain below the core design limit, the remaining fuel rods then will presumably fall within this limit. As discussed before, C4 and $\mathrm{C} 10$ are the hottest rods for up to 200 MWD and 700 MWD core burnt, respectively, so the major focus of this study whether temperature of these hottest rods remain below the design limit.

In his study, major parameters such as fuel centerline temperature, fuel cladding temperature, bulk coolant temperature at different cycles of core burnup are being calculated considering the reactor operates at $3 \mathrm{MW}$ power during steady state operation. Prior to the analysis by EUREKA-2/RR, some preliminary data have to be be generated. Kaminaga[5] developed three utility codes to produced the entire input data of EUREKA-2/RR which are DISSUE, ICETEA and PREDISCO such as DISSUE calculates power fraction and void, Doppler, clad expansion and coolant temperature reactivity weighting factors for each heat slab based on core neutronic calculation, ICETEA calculates coolant temperature distribution and PREDISCO calculates pressure distributions in the coolant.

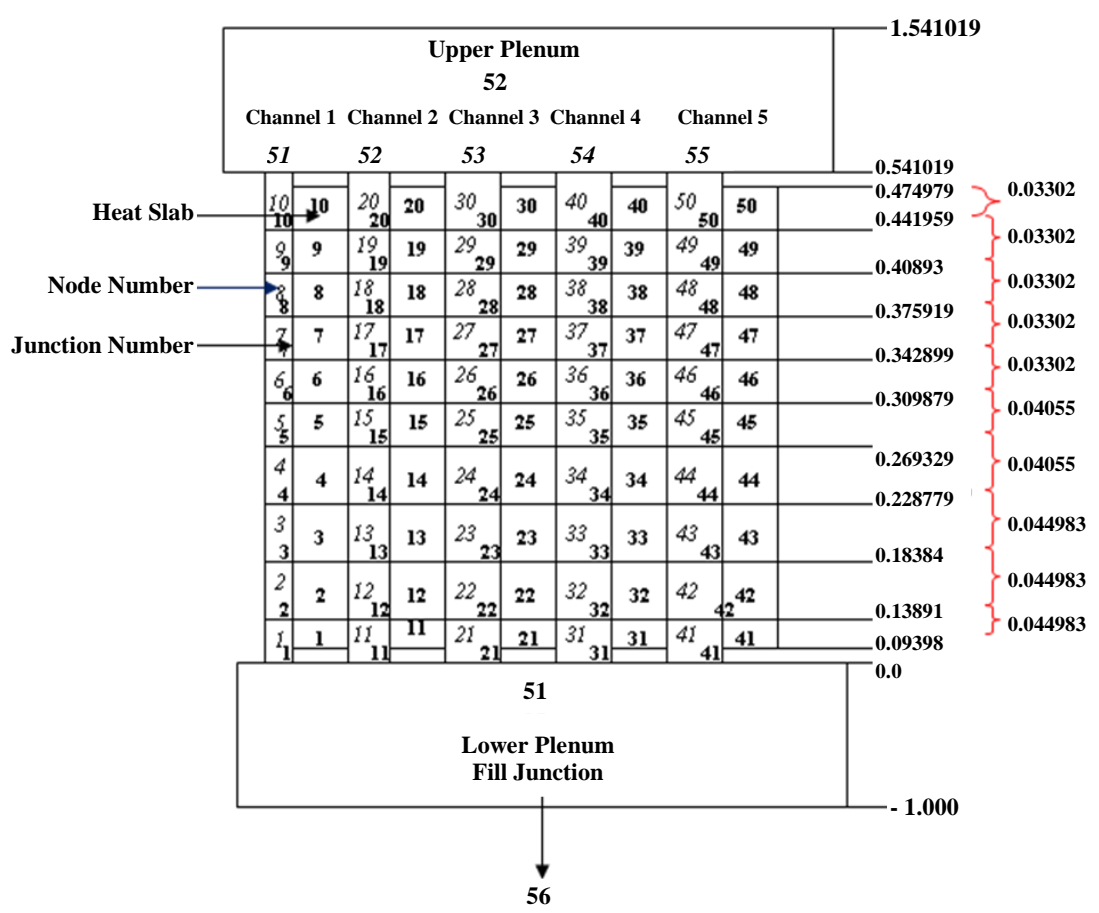

Fig. 5. Schematic diagram of the model prepared for EUREKA-2/RR analysis. 


\section{RESULTS AND DISCUSSION}

The peak temperatures of fuel centerline, clad and bulk coolant of the hottest fuel element, $\mathrm{C} 4$, are reported in Table 3 considering beginning of cycles of $75 \mathrm{MWD}$ and $150 \mathrm{MWD}$ burnt core for reactor operated at $3 \mathrm{MW}$ power under steady state condition. It is seen that peak temperatures of fuel centerline and clad with associated bulk coolant temperatures decrease as total peaking factors decreases with the increase of burnup. Similarly, the same Table 3 contains the temperatures data for the next cycle hottest rod, C10. It is noticed that the peak temperatures of fuel centerline, clad and bulk coolant temperatures for the $\mathrm{C} 10$ hottest rod increases with 550 MWD and 700 MWD cycles due to increase of total peaking factors with the progress of burnup. Figures 6 and 7 present the axial distribution of temperature in the hottest channels C4 and C10 for 150 MWD and 700MWD burnt of TRIGA core, respectively.

Table 3. Temperatures of hottest channels at different cycles of core burnup.

\begin{tabular}{lccccc}
\hline Parameters & \multicolumn{1}{c}{ C4 } & \multicolumn{2}{c}{ C10 } \\
\hline & BOC & $\begin{array}{c}\mathbf{7 5} \\
\text { MWD }\end{array}$ & $\begin{array}{c}\text { 150 } \\
\text { MWD }\end{array}$ & $\begin{array}{c}\mathbf{5 5 0} \\
\text { MWD }\end{array}$ & $\begin{array}{c}\text { 700 } \\
\text { MWD }\end{array}$ \\
\cline { 2 - 6 } & & 46.67 & 46.66 & 46.67 & 46.94 \\
$\begin{array}{l}\text { Bulk Coolant } \\
\text { Temperature, }{ }^{\circ} \mathrm{C}\end{array}$ & 46.74 & & & & \\
$\begin{array}{l}\text { Cladding } \\
\text { Temperature, }{ }^{\circ} \mathrm{C}\end{array}$ & 136.75 & 136.28 & 136.15 & 135.64 & 137.54 \\
$\begin{array}{l}\text { Fuel Centerline } \\
\text { Temperature, }{ }^{\circ} \mathrm{C}\end{array}$ & 703.16 & 697.31 & 695.79 & 689.22 & 712.79 \\
\hline
\end{tabular}

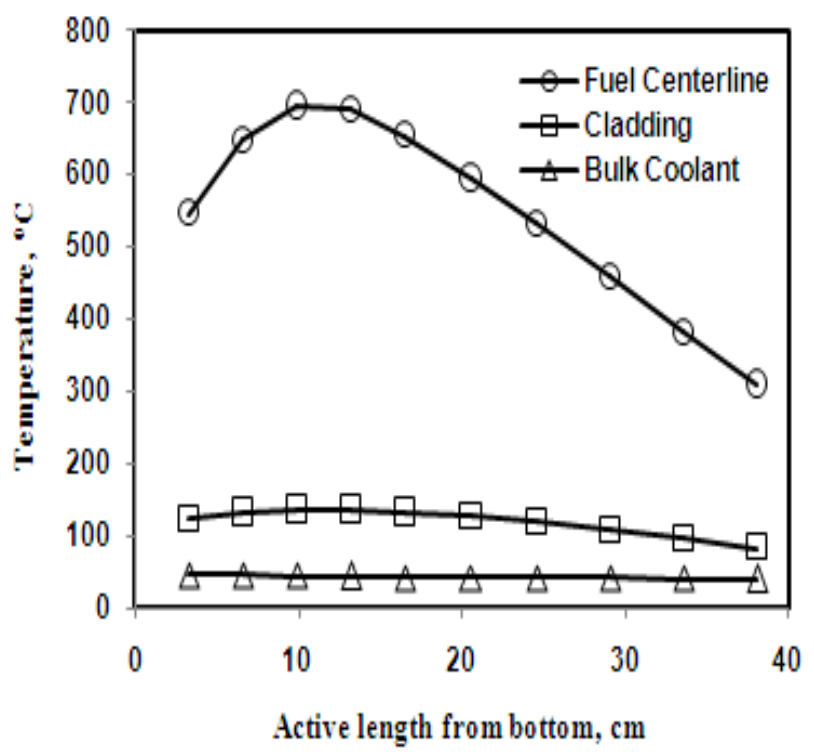

Fig. 6. Axial temperature distribution in the hottest channel of C4 at 150 MWD burnt condition.

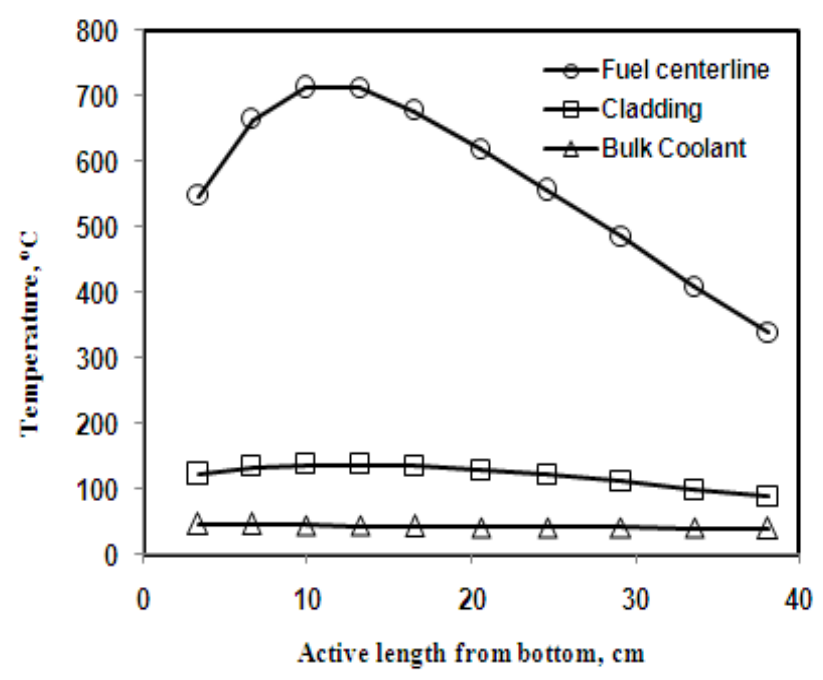

Fig. 7. Axial temperature distribution in the hottest channel of C10 at 700 MWD burnt condition.

\section{CONCLUSION}

The burnup dependent steady state thermal hydraulic analysis has been carried out which shows that maximum temperatures of the hottest channel strictly depends on cycles of core burnup. Although there is temperature change in the hottest channel either decrease or increase with the progress of burnup, however, this change seems very little. Moreover, maximum temperature reported for fuel clad and fuel centerline found to lie below their design limit, $500^{\circ} \mathrm{C}$ and $950^{\circ} \mathrm{C}$, respectively which indicates that there is no chance of burnout on the fuel cladding surface and no blister in the fuel meat throughout the considered cycles of core burnt.

\section{ACKNOWLEDGMENT}

The authors would like to acknowledge Dr. Masanori Kaminaga of Japan Atomic Energy Agency (JAEA) for his generous support and willingness to make comments and discussions during the progress of the work. Thanks will also go to director, INST for giving permission to carry out such analysis.

\section{REFERENCES}

1. M.Q. Huda, S.I. Bhuiyan, T. Obara., Ann. Nucl. Energy 35 (2008) 141.

2. M. Rahman, M.S. Mahmood, M.T. Chowdhury, et al., Fuel Burnup and Core Life Time Calculation of the TRIGA Mark-II Research 
Reactor of Bangladesh Atomic Energy Commission, FNCA Report (2008).

3. M.S. Mahmood, Z.I. Lyric, M.A. Motalab, et al., Individual Fuel Element Burnup of BAEC TRIGA Core, Technical Report, INST-RPEDRARD-01/009 (2012).

4. M. Kaminaga, EUREKA-2/RR Code, Japan Atomic Energy Agency (1996).
5. M. Kaminaga, Preliminary Reactivity Insertion Accidents Analysis of the Multi-Purpose Research Reactor RSG-GA Siwabessy Using EUREKA-2 Code, Japan Atomic Energy Research Institute, JAERI-memo: 03-176 (1991).

6 N.H. Badrun, M.H. Altaf, M.J.H. Khan, et al., Ann. Nucl. Energy 41 (2012) 40. 